\title{
Mobile learning and socially constructed blended learning through the lens of Activity Theory
}

\author{
Vickel Narayan, Thomas Cochrane, Stephen Aiello, James Birt, Mehrasa \\ Alizadeh, Neil Cowie, Paul Goldacre, David Sinfield, Todd Stretton, Tom \\ Worthington, Chris Deneen, Michael Cowling
}

Massey University, University of Melbourne, Auckland University of Technology, Bond University, Osaka University, Okayama University, University of Queensland, AUT University, Auckland University of Technology, Australian National University, University of Melbourne, Central Queensland University

\begin{abstract}
The pandemic has drastically changed the education landscape. The pedagogical practices, policies and procedures ingrained and refined over many years were suddenly rendered less effective. Overnight, new practices, policies and procedures had to be drafted to support teaching and learning. More than a year on, educators have found a new home, new pedagogies and practices have been refined and continue to be, policies and procedures are agile to support a volatile environment academia dwells in during the pandemic era. Building upon the work the Mobile Learning Special Interest Group (MLSIG) presented last year at the conference, we investigate the role mobile learning is and could play in emerging pandemic pedagogies. Eight vignettes are presented from universities around the world that are analysed using Activity Theory to understand the role of mobile devices and social tools for developing blended synchronous learning (BSL) and HyFlex learning.
\end{abstract}

Keywords: mobile learning, COVID-19, blended synchronous learning, hyflex, activity theory

\section{Overview}

Last year the Mobile Learning Special Interest Group proposed the mobile ecology of resources concept (Narayan, Cochrane, et al., 2020) to provide guidance to educators for using mobile affordances for designing for learning amidst a global pandemic. It focused on the notion of 'uncoupled learning' where learning was not tethered to scheduled time and space. At the peak of the pandemic, the limitations that were imposed to control the spread of the virus meant learning perhaps for the first time was truly determined by the learner. This was a dominant pedagogical shift on a massive scale. More critically, the learners gained control over space and time and hence could determine where to learn and how, enabled by mobile devices (Sugden, Brunton, et al., 2021).

We remain in a state of flux of COVID-19 disruption, and this further complicates how learning is facilitated, where some students are able to physically attend a class on campus, while others are not. Against this backdrop, Ferdig and Pytash (2020) posit that a new 'workable balance of in-person and digital learning must be found to motivate and educate all students' (p. 9). To mitigate the challenges of the volatile context postlockdown period, educators have turned to either BSL (Bower, Dalgarno, et al., 2015) or HyFlex approach (Beatty, 2008) that have existed for over a decade. While BSL and HyFlex learning approaches are often used synonymously, they offer different opportunities and challenges (refer Miller, Sellnow, \& Strawser, 2021). A shared element in BSL and HyFlex is the use of technology and its affordances for creating the learning environment - for connecting the students, providing agency and autonomy, and facilitating a seamless, engaging and interactive learning experience (Ferdig \& Pytash, 2020). Of particular interest to the MLSIG is how mobile devices are integrated into the learning and teaching process and the effect it has on the learning process.

To understand the complexity of designing effective HyFlex or BSL courses, we have to first understand the intricate interplay between different facets that inform and play an integral part in the learning process. A further complication to this equation is to understand the role mobile learning could play in the process. To help dissect this, we looked to Activity Theory (AT) (Engeström, 2001) to provide a framework for considering the different entities and facets and the interplay between them as an ecology for designing for learning with mobile devices 
(Bozalek et al., 2014). AT delineates learning into several elements to understand and examine learner interactivity in socio-cultural settings that are made of entities and artefacts in a space at a given time (Engeström, 2001; Rozario, Ortlieb, \& Rennie, 2015). As a result, learning in AT is viewed as an interplay between tools (mediating artefacts), subjects (actors), object(ive) (goals), rules (constraints and guidelines), community and division of labour (who controls it) — together forming the activity system (Engeström, 2001).

In this concise paper, we provide eight vignettes from universities around the world that briefly discuss how mobile devices are being used during the post-lockdown pandemic era to support learning. We then analyse the case studies using AT to understand what role mobile devices and other tools play in different contexts to engage the students in the learning process.

\section{Methodology}

Eight vignettes reflecting on adapted learning expe57riences over the last year were shared in collaborative meetings with twelve [of the 70] members of the MLSIG. These members are affiliated with universities in Australia, New Zealand, Japan, and the U.K. The reflections were first shared in the MLSIG meeting, and the members were then invited to compose a vignette to be included in this concise paper and for the accompanying poster for the conference.

\section{Case Study Vignettes}

\section{Case 1-Mobile Technology for The Graphic Designer}

Teaching graphic design is always going to be a challenging prospect when faced with not being in person in the same classroom. There is a certain amount of content that can be delivered as a lecture (which is easily adapted online) but there are also the one-on-one and group discussions that are of equal importance that tend to be more challenging when this has to be delivered online. Using Blackboard and Microsoft Teams has now become the standard delivery mode, and whilst these have proven successful, it does, however, pose issues when trying to communicate with the graphic design student, especially when they are wanting feedback on their artistic work. Trying to accomplish this online in the written vernacular can be time-consuming and confusing to the student; normally in an in-person environment, this would be a discussion with the students and their work. Faced with this dilemma the graphic design teacher needs to be adapted to ways of communicating feedback for visual content online. To overcome this, I used a stylus-based tablet and software such as Surface Pro and OneNote. This enabled me to give instant feedback to the students' visual designed project work they posted online through OneNote, and thus eliminated lengthy written emails that could possibly be misconstrued when presented with visual content.

\section{Case 2-Hybrid Model United Nations}

Okayama University in western Japan offers one elective course called Model United Nations (MUN). The class prepares students to take part in a simulated role-play in which they each represent one country as its delegate. In 2020 all lessons were online but from April 2021 they reverted to face-to-face. Unfortunately, two students were stranded outside of Japan (in the UK and Taiwan) at this time. In response, the teacher created a hybrid lesson in which 15 students met in a socially distanced classroom and the two remote students joined Zoom. The Zoom screen was visible on the teacher's laptop but could not easily be seen by the face-to-face students unless they walked over to the laptop. Most class activities involve students discussing various global issues in rotating groupings reflecting the MUN framework (regional country blocs and various committees). In order to participate actively, the two remote students accessed the Japanese social network application, LINE, to create different student groups using their smartphones. One student in each classroom group would open the application and the remote students could be seen and could communicate with everybody. MUN delegates try to propose practical solutions to real-world problems and this hybrid class was a good example of this.

\section{Case 3-Paramedic Clinical Education}

Auckland had several lockdowns throughout 2020 so I developed a flipped classroom approach to my teaching using the Adobe Spark software for semester one 2021. Pre-COVID-19, I would deliver a four hour face-to-face lecture each week using PowerPoint slides. Whilst the flipped classroom is not new, my intent was to make content more accessible and promote stability within an uncertain climate. Adobe Spark allowed me to structure lectures in an audio/video blog format with limited screen detail so as to allow the content to be delivered on a mobile device such as a phone/headphones/iPad or computer. Historically, my students would furiously take 
notes which would at times hinder their ability to participate in the wider class discussion. Following the change to the new model, engagement statistics and interaction showed that on average each student would watch each of the thirty 10-minute videos at least four times. Also of note, the grade average for this paper shows dramatic improvement. In conclusion, the delivery of lecture material in a video/auditory format suitable for a wide range of mobile devices allowed students greater control regardless of lockdown and offered the ability to review and reflect upon the lecture content on multiple occasions that resulted in higher grades.

\section{Case 4-Architecture, Engineering and Construction Site Visits}

Spatial visualisation skills are important for learners within the Architecture, Engineering and Construction (AEC) industry. These skills allow for 2D-3D translation of plan drawings to human scale locations. PreCOVID-19 the standard practice for spatial skill development within AEC education was the use of site visits, 360 video, immersive virtual reality (VR) and $2 \mathrm{~d}$ drawings to support learners. However, the move to remote and multimodal blended learning has reduced the availability of physical sites and VR based equipment to support learners. At Bond University the mixed reality research lab took up the challenge to bring the buildings to the learners through their BYOD smartphones through a hybrid Augmented Reality (AR) - 360 integration. The BuildingAR app built using Unity and AR Foundation for Android and iOS utilises a building information model of a building on campus including multiple layers (structural, mechanical, hydro, electrical) and fixed location high resolution 360 images to support learners to transition from the low-resolution 3D models to high fidelity 360 images. The tool is supported with an LMS enabled QR code, onboarding videos and lesson plan that guides the learners through the pedagogical method. The tool has successfully been deployed across four trimesters (May/Sep 2020 remote and Jan/May 2021 blended) with more than 250 postgraduate and undergraduate learners at Bond University.

\section{Case 5-Designing for Online, Blended and Synchronous Learning for Computing Students}

By mid 2021, I had completed a third semester teaching reflective learning with an e-portfolio to computer project students online at the Australian National University (ANU). A blended approach used no conventional lectures or examinations, replacing them with group workshops and individual assignments, with peer assessment. It was designed in 2019 to adapt to the needs of the students, online, or on campus, during an emergency which closed the campus, with uninterrupted participation by international students (Worthington, 2014). The online option was used from semester 1 2020, due to COVID-19. Workshops were replaced with Zoom video conferencing, while other activities and assessment were unchanged (delivered via the Moodle Learning Management System). For Semester 2, 2021, it is planned to implement a hybrid mode, with students on campus linked to the others online via Zoom. For group work the students will be divided into separate teams, either in the physical classroom or in a virtual Zoom "room", to lessen communication problems. If the campus is closed, earning will revert to pure online mode again, with all students in Zoom rooms.

\section{Case 6-Immersive Virtual Reality for Social Learning}

Since April 2020, most classes at Osaka University have been shifted to synchronous online, asynchronous ondemand format, or a mixture of both. The problem that most instructors, especially in synchronous language learning classes, have been struggling with is the absence of active student participation. A significant number of students are camera shy and not always willing to express themselves in a second language. As a solution to this problem, my colleagues and I have been experimenting with immersive virtual reality (VR), hypothesising that these environments are potentially more motivating and welcoming for students to engage in authentic interaction. We are still at the preliminary stage of testing out various tools among ourselves or with a small number of students. To start, we created on-demand video learning materials in Engage, a VR communication platform. Those videos were recorded and delivered to the students on demand in Russian beginners' course. In addition, there are a growing number of social VR apps to experiment with other than Engage, and recently we have begun using Mozilla Hubs for a learner-generated VR content creation project, where students make their own rooms in Hubs to introduce an aspect of their academic discipline to peers.

\section{Case 7-Virtual Physiotherapy Learning and Assessment}

The disruption of COVID-19 in New Zealand led to a flurry of academics (re)considering pedagogy and critical thinking in virtual spaces. This included the physiotherapy program at AUT University as lecturers adapted teaching and learning strategies to deliver and demonstrate competency of knowledge and practical skills. Other than uploading lecture slides, lab worksheets and links to online resources, the program was novice in the delivery of online synchronous and asynchronous learning. This proved most challenging with the adaption of 
hands-on modelling, supervising, and assessing practical skills. The majority of lecturers required training on the development of asynchronous recordings of lectures (Panopto) as well as synchronous small group sessions (Blackboard Collaborate). Lecturers pre-recorded practical tasks (sometimes using family/ housemates as models within their "COVID bubble") as it was identified existing online resources were inadequate. Assessments were reconsidered to enable online asynchronous (e.g., practical skills video) and synchronous submission (e.g., verbal assessments using teleconferencing software- i.e., Teams).

\section{Case 8-DIY Durability Lab-Timber Engineering}

With the rapid pivot to fully online learning in semester 1, 2020 the teaching team for Design of Timber Structures at UQ, had to manage the uncertainties related to returning to on-campus labs in semester 2. Furthermore, some students continued to study overseas or remotely in Australia. Finally, the risk of a " 2 nd wave" was very real as this was occurring overseas. Prior to COVID-19, one of the on-campus assessments was a durability lab. The task was to assess the durability of a timber structure, such as a timber bridge or walkway as a group exercise, utilising their mobile devices, identifying any decay and making suggestions for mitigation and maintenance strategies going forward. During COVID-19 the teaching team had to pivot the assessment to what was coined a 'DIY Durability Lab' where students could choose a localised timber structure such as a picnic shelter, utility pole, park bench or a timber temple, allowing students to stay within their local neighbourhood while working on this assignment in their own time. In this case study, the DIY lab reflected, in an authentic way, what a structural timber engineer would do when assessing the durability performance of a timber structure. Giving the students the opportunity to choose their own timber structure and examine it with their own BYOD gave students the autonomy to manage their own time and the consequent sense of ownership of the project.

\section{Discussion}

The analysis of the eight case studies provided a snapshot of the general state of designing for learning at various stages of the pandemic. The early stage includes a pivot to online learning where online learning was prepared in haste and at times without appropriate pedagogy. This is followed by a stage of considered design principles for online learning, and then the possibility of BSL and HyFlex learning when the lockdowns were lifted. The later stages demonstrate that with time considered design methods and principles were used to guide the teaching and learning practices in HyFlex and BSL modes (Ferdig \& Pytash, 2020).

Figure 1. Mapping of the eight case studies onto the AT framework (Engeström, 2001)

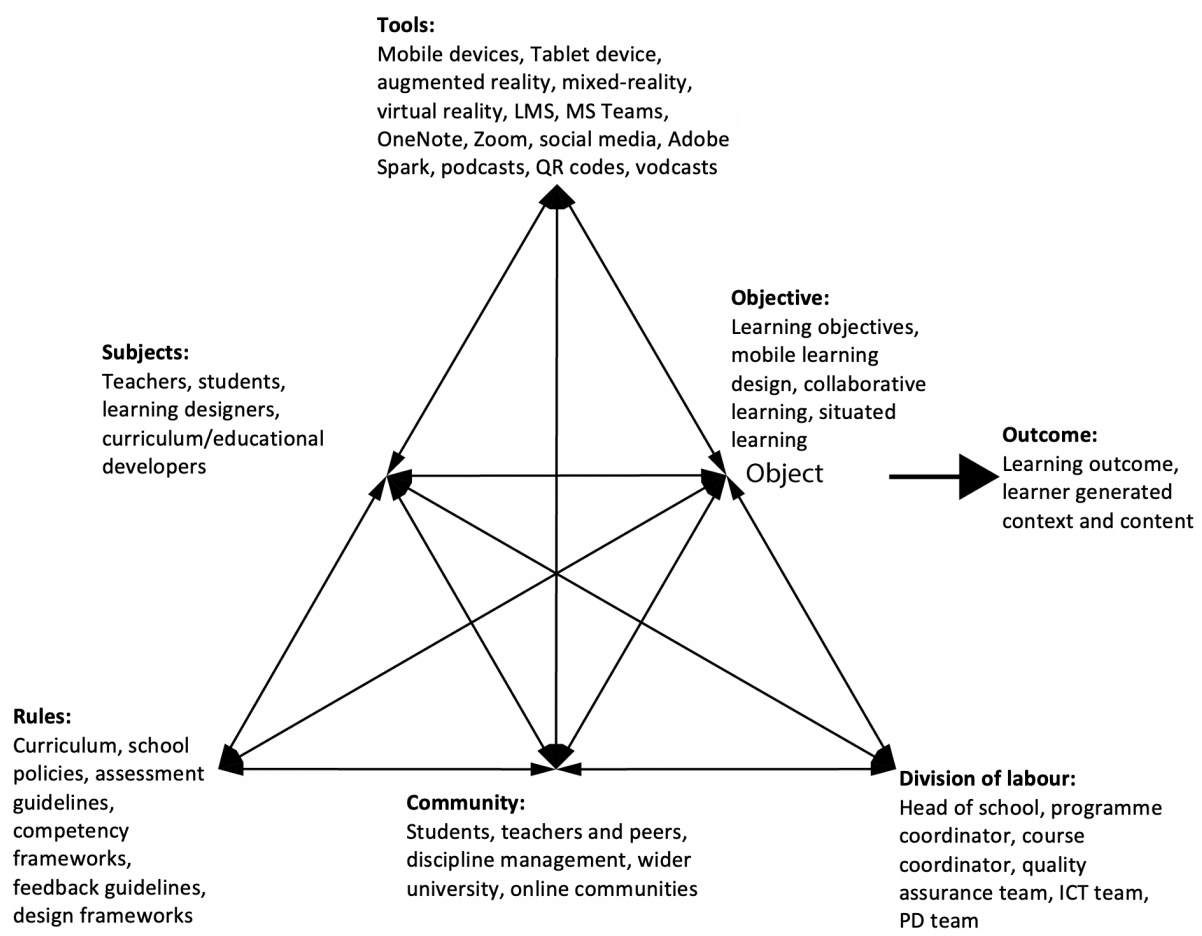


Figure 1 represents the findings from the case studies mapped onto the AT framework. It suggests that the use of mobile devices and collaborative tools for learning and teaching during the pandemic enabled a connection between the students and the student and the teacher (tools-subjects' relationship in Figure 1). The mobile affordances further amplified the interactivity of the students within the activity system (tools-community relationship). It facilitated conversation, communication, enactment of applied practice, collaboration, and the ability for the learners to connect with peers and external communities to construct knowledge and meaning (tools-subjects - community relationship in Figure 1). The embodiment of mobile devices and social tools into everyday life ensured that the learners were able to engage in or create authentic contexts for learning (toolssubjects - community - objective - outcomes relationship in Figure 1) - application of knowledge in a meaningful environment determined by the student to create content and new knowledge (Cochrane, 2021; Narayan, Herrington, \& Cochrane, 2019).

The case studies shared in this concise paper highlighted that mobile devices and collaborative tools were imperative in the design for learning in HyFlex and BSL modes. It acted as the mediating agent (bonding agent) that connected the different ecologies represented in Figure 1 into a cohesive ecology of resources for the students to interact and act in (Narayan, Cochrane, Birt, \& et. al, 2020). While the students are still engaging in a task or learning activity, they, however, did so at a time and space deem appropriate by them - ensuring the ecology co-constructed by the student cohort was active and accessible whenever the students needed it (Narayan, Herrington, Cochrane, 2019; Cochrane, Narayan, Birt, \& et. al, 2020). This suggests that mobile and collaborative tools were able to provide the students creative freedom in the learning process within the limitations imposed by the rules and division of labour vertices.

\section{Conclusion}

Pandemic pedagogies are emerging and are being refined at a fast rate. They are not new, BSL and HyFlex learning modes have existed for many years now but have gained renewed interest during this time. In this concise paper, we analysed eight case studies of mobile learning designs using AT. The findings suggest that mobile devices and social tools are critical in achieving a balance between learning and teaching in the pandemic era. Pandemic literature over the last year has mostly focused on using tethered devices for designing and facilitating learning (Ferdig \& Pytash, 2020), we, however, espouse that mobile devices and their affordances should also be given equal consideration. Mobile devices enable continuous connectivity to social settings and contexts that are not bound by time. This helps the learner connect with and act upon the ecologies (Figure 1) critical for creating knowledge and meaning. It helps the students create content and new contexts for learning that is determined by the learning needs at the time. The ecologies, as a result, are not static or the responsibility of the teacher. They are socially co-constructed by the students with guidance from the teacher when needed and become embedded in the learning and teaching processes. As a result of this study, the MLSIG will be embarking on a meta-analysis study of literature during the pandemic. We aim to explore, investigate and understand how mobile learning and design could be utilised for the emerging socially constructed blending learning pedagogies.

\section{References}

Beatty, B. (2008). Using the 'Hyflex' course and design process. San Francisco State University. https://tinyurl.com/2zjam3x4

Bower, M., Dalgarno, B., Kennedy, G. E., Lee, M. J., \& Kenney, J. (2015). Designing and implementation factors in blended synchronous learning environments: outcomes from a case-case analysis. Computers \& Education, 86(August), 1-17. https://doi.org/10.1016/j.compedu.2015.03.006

Bozalek, V., Ng'ambi, D., Wood, D., Herrington, J., Hardman, J., \& Amory, A. (2014). Activity theory, authentic learning and emerging technologies: Towards a transformative higher education pedagogy. Routledge. https://doi.org/10.4324/9781315771823

Engeström, Y. (2001). Expansive learning at work-toward an activity theoretical reconceptualization. Journal of Education and Work, 14(1). https://doi.org/10.1080/13639080020028747

Ferdig, R. E., \& Pytash, K. E. (2020). What teacher educators should have learned from 2020. Association for the Advancement of Computing in Education (AACE). https://www.learntechlib.org/primary/p/219088/

Miller, A. N., Sellnow, D. D., \& Strawser, M. G. (2021). Pandemic pedagogy challenges and opportunities: instruction communication in remote, HyFlex, and BlendFlex courses. Communication Education, 70(2). https://doi.org/10.1080/03634523.2020.1857418

Narayan, V., Cochrane, T., Birt, J., \& Cowie, N. (2020). A mobile ecology of resources for Covid-19 learning. In ASCILITE 2020: 37th International Conference on Innovation, Practice and Research in the Use of 
Educational Technologies in Tertiary Education (pp. 1-5). Australasian Society for Computers in Learning in Tertiary Education. https://2020conference.ascilite.org/wpcontent/uploads/2021/04/ASCILITE-2020-Proceedings-Narayan-V-et-al.pdf

Narayan, V., Herrington, J., \& Cochrane, T. (2019). Design principles for heutagogic learning: Implementing student-determined learning with mobile and social media tools. Australasian Journal of Educational Technology (AJET), 35(3), 86-101. https://doi.org/https://doi.org/10.14742/ajet.3941

Rozario, R., Ortlieb, E., \& Rennie, J. (2015). Interactivity and mobile technologies: an activity theory perspective. In D. Churchill, J. Lu, T. Chiu, \& B. Fox (Eds.), Mobile Learning Design. Lecture Notes in Educational Technology. Springer. https://doi.org/10.1007/978-981-10-0027-0 4

Sugden, N., Brunton, R., MacDonald, J., Yeo, M., \& Hicks, B. (2021). Evaluating student engagement and deep learning in interactive online psychology learning activities. AJET, 37(2). https://doi.org/10.14742/ajet.6632

Worthington, T. (2019, December). Blend and flip for teaching communication skills to final year international computer science students. In 2019 IEEE International Conference on Engineering, Technology and Education (TALE) (pp. 1-5). IEEE. https://doi.org/10.1109/TALE48000.2019.9225921

Miller, A. N., Sellnow, D. D., \& Strawser, M. G. (2021). Pandemic pedagogy challenges and opportunities: instruction communication in remote, HyFlex, and BlendFlex courses. Communication Education, 70(2). https://doi.org/10.1080/03634523.2020.1857418

Narayan, V., Cochrane, T., Cowie, N., Goldacre, P., Birt, J., Sinfield, D., Alizadeh, M., \& Worthington, T. (2021). Mobile learning and socially constructed blended learning through the lens of Activity Theory.

In Gregory, S., Warburton, S., \& Schier, M. (Eds.), Back to the Future - ASCILITE '21. Proceedings ASCILITE 2021 in Armidale (pp. 166-171). https://doi.org/10.14742/ascilite2021.0123

Note: All published papers are refereed, having undergone a double-blind peer-review process.

The author(s) assign a Creative Commons by attribution licence enabling others to distribute, remix, tweak, and build upon their work, even commercially, as long as credit is given to the author(s) for the original creation.

(C) Narayan, V., Cochrane, T., Cowie, N., Goldacre, P., Birt, J., Sinfield, D., Alizadeh, M., \& Worthington, T. 2021 